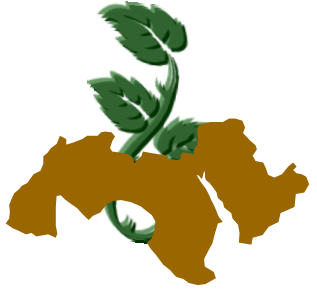

\title{
PROTECTIVE EFFECT OF CINNAMON, CLOVE AND GINGER SPICCES OR THEIR ESSENTIAL OILS ON OXIDATIVE STRESS OF STREPTOZOTOCIN-INDUCED DIABETIC RATS
}

\author{
Naglaa H.M. Hassanen ${ }^{1}$ \\ 1- Special Food and Nutrition Department, Food Technology Research Institute, Agricultural \\ Researche Center, Giza, Egypt
}

Keywords: Cinnamonum zeylanicum , Syzygium aromaticum, Zingiber officinale, spices, essential oils, Streptozotocin (STZ), rat

\begin{abstract}
In an attempt for utilization of some common spices, cinnamon bark, clove bud and ginger rhizom are popular implementations because of their flavoring and antioxidative activity, which mainly comes from polyphenols. The aim of the study was to investigate the effect of spices or their essential oils compared with Diamicron30MR $(60 \mathrm{mg} / 100 \mathrm{~g}$ diet) on the occurrence of oxidative stress in serum of induced diabetic rats by measuring the extent of oxidative damage as well as the status of the antioxidant defense system. Albino rats weighing 150 $\pm 5 \mathrm{~g}$ were injected with STZ $(50 \mathrm{mg} / \mathrm{kg})$ intraperitoneally for induction of diabetes mellitus. Rats were divided into 17 groups (each of 8 rats) of nondiabetic ,diabetic non-treated and diabetic treated rats with spice powders or their essential oils and mixtures. After 8 weeks, the diabetic rats fed on spices or their essential oils significantly decreased levels of blood glucose and significantly increased insulin level. The treatment also resulted in a significant improvement in lipid profile, liver functions and kidney functions. However, a significantly increment in the activities of glutathione peroxidase (GPH-Px) and concentration of glutathione (GSH) were observed in blood of diabetic rats treated with all of the essential oils. The treated groups showed a significant decrement in thiobarbituric acid reactive substances (TBARS) in serum. Since the study of induction of the redox enzymes is considered to be a reliable marker for evaluating the antiperoxidative efficacy of the spices, these findings sug-
\end{abstract}

gest a possible antiperoxidative role derived from such essential oils. Treatment with spices or their essential oils reduces the hepatic, renal, pancreatic and cardiac histopathological abnormalities associated with STZ - induced diabetes mellitus.

\section{INTRODUCTION}

Oxidative stress, defined as an imbalance between oxidants and antioxidants leads to many biochemical changes and is an important causative factor in several human chronic diseases, such as atherosclerosis and cardiovascular diseases, mutagenesis and cancer, several neurodegenerative disorders and the aging process (Vijayakumar et al 2006). Diabetes mellitus is one of these diseases and it is estimated that the number of diabetic patients will continue to increase in the future (Furusho et al 2002). Diabetes is a multifactorial disease, which is characterized by hyperglycemia and lipoprotein abnormalities (Scoppola et al 2001). These traits are hypothesized to damage cell membranes, which results in elevated production of reactive oxygen species (ROS). This generation of oxygen-free radicals during cellular metabolism, and by certain environmental factors, including lifestyle appears to play a critical role in the pathogenesis of diabetes (Hartnett et al 2000). Antioxidants provide protection to living organism from damage caused by uncontrolled production of ROS concomitant lipid peroxidation, protein damage and DNA strand breaking. Many minor components of foods, such as secondary plant metabolites, have been shown to alter biological processes, which may reduce the risk of chronic diseases in diabetic humans (Gupta et al 2008). Cinnamon is one of the traditional folk herbs used in 
Korea, China and Russia for diabetes mellitus. Cinnamon is the bark of the Cinnamomi cassiae (Lauraceae). Cinnamic aldehyde, cinnamic acid, tannin and methylhydroxychalcone polymer (MHCP) (Badee et al 2005a) are its main componets. Qin et al (2003); Alam et al (2003); Kim et al (2006) and Subash Babu et al (2007) have recently reported that cinnamon extract decreases blood glucose in rats, has hypolipidemic effect (Lee et al 2003; Badee et al 2005b and Kannappan et al 2006), increases the insulin sensitivity and glucose uptake in adipocytes (Jarvull-Taylor et al 2001). Clove was also the most bioactive, followed by witch hazel, green and black tea, allspice, bay leaves, nutmeg,cinnamon, mushrooms and brewer's yeast (Broadhurst et al 2000). Specific plant-derived compounds also regulate glucose metabolism (Prasad et al 2005).

Zingiber officinale Roscoe (family, Zingiberaceae), known commonly as ginger, is consumed worldwide in cookeries as spice and flavoring agent. It has been used as spice and medicine for thousands of years. Antioxidants in ginger include gingerols, shogaols and some related phenolic ketone derivatives. Its dried extract contains monoterpens and sesquiterpens. Ginger extract has antioxidative properties and scavenges superoxide anion and hydroxyl radicals (Badee et al 2005b). Feeding rats on ginger significantly elevated the $\begin{array}{llll}\text { activity of hepatic cholesterol } 7 & \end{array}$ a-hydroxylase which is a rate-limiting enzyme in the biosynthesis of bile acids and stimulates the conversion of cholesterol to bile acids leading to the excretion of cholesterol from the body (Srinivasan and Sambaiah 1991). Ethanolic gingerextract consumption has also been shown to reduce plasma cholesterol and inhibit LDL oxidation in atherosclerotic, apolipoprotein E-deficient mice (Ahmed et al 2000 and Fuhrman et al 2000). Afshari et al (2007) and Al-Qattan et al (2008) have recently reported that ginger extract decreases blood glucose in rats.

The present study was undertaken to investigate the effect of spices or their essential oil extracts of cinnamon, clove and ginger on streptozotocin-induced diabetic comparing to Diamicron 30MR.

\section{MATERIALS AND METHODS}

\section{Materials}

Spices: the following spices, Cinnamon (Cinnamomum zeylancium), Clove (Syzygium aromati- cum) and Ginger ( Zingiber officinale ) were purchased from Pharmaceutical Science Laboratory, National Research Centre, Giza, Egypt.

Diamicron30MR was purchased from a pharmacy.

Streptozotocin: was purchased from Sigma Chemical Co. ( St.Louis. Mo).

Kits of (Glucose, Total cholesterol, High density lipoprotein cholesterol (HDL), Low density lipoprotein cholesterol (LDL), Triglycerides (TG), Alanine amino transferase (ALT), Aspartate amino transferase (AST), Alkaline phosphatase (AP), Creatinine, Urea, Uric acid, Malondialdehyde (MDA), reduced Glutathione (GSH) and Glutathione peroxides (GSPX) were obtained from Randox Laboratories Ltd., Diamond Road, Crumlin, Co., Antrim, United Kingdom, BT294QY. The insulin kit was obtained from Biosource Europe S.A., B-1400 Nivelles, Belgium. Insulin was measured by InsELISA.

\section{Methods}

Extraction of essential oils from spices: The essential oils of cinnamon, clove and ginger fruits were obtained by water distillation using a (Clevenger-type apparatus) for 4 hours. The separated volatile oil was dried over anhydrous sodium sulphate before holding glass bottles at $-20^{\circ} \mathrm{C}$, according to Guenther (1961).

\section{Animal feeding experiment}

Hundred thirty six young male Albino rats, average weight of $150 \pm 5 \mathrm{~g}$., raised in the animal house of the Ophthalmology Research Institute, Giza, Egypt, were used in the present study. The rats were kept under normal healthy laboratory conditions; temperature was adjusted at $25 \pm 2{ }^{\circ} \mathrm{C}$ and 12 hour light - dark periods. Animals were adapted on free access of water, and fed for one week on standard basal diet before the initiation of the experiment.

Composition of the basal diet $(\mathbf{g} / \mathbf{k g})$ : $\mathrm{Ca}$ sein, $10 \%$; cellulose, $5 \%$; corn oil, $10 \%$; corn starch, $70 \%$; salt mixture, $4 \%$ and vitamin mixture, $1 \%$ according to Lane Peter and Pearson (1971).

Design: After the adaptation period, diabetes mellitus was induced by intraperitoneal injection of $50 \mathrm{mg} / \mathrm{kg}$ body weight streptozotocin dissolved in $0.2 \mathrm{~m}$ mole sodium citrate at $\mathrm{pH} 4.5$ according to the method described by Lutz and Pardridge 
(1993). Blood samples were collected after 48 hours of injection and glucose levels were determined. Rats with blood glucose levels about 320 $\mathrm{mg} / \mathrm{dl}$ were considered to be diabetic animals. Seventeen groups of rats (8 rats each) were studied according to the following scheme for 60 days: (N. control) negative control (non diabetic rats), ( $P$. control) positive control (untreated diabetic rats), (Diamicron) diabetic rats fed on basal diet containing Diamicron30MR (60 mg/100 g diet), (cinnamon $2.5 \mathrm{~g}$ ) diabetic rats fed on basal diet containing cinnamon powder (2.5 g / $100 \mathrm{~g}$ diet), (clove $2.5 \mathrm{~g}$ ) diabetic rats fed on basal diet containing clove powder (2.5 g /100 g diet),(ginger $2.5 \mathrm{~g}$ ) diabetic rats fed on basal diet containing ginger powder ( $2.5 \mathrm{~g} / 100 \mathrm{~g}$ diet), (cinnamon + clove $2.5 \mathrm{~g}$ ) diabetic rats fed on basal diet containing a mixture of $1: 1$ cinnamon and clove powders $(2.5 \mathrm{~g} / 100 \mathrm{~g}$ diet $)$, (cinnamon+ ginger $2.5 \mathrm{~g}$ ) diabetic rats fed on basal diet containing a mixture of $1: 1$ cinnamon and ginger powders $(2.5 \mathrm{~g} / 100 \mathrm{~g}$ diet $)$, (clove + ginger $2.5 \mathrm{~g}$ ) diabetic rats fed on basal diet containing a mixture of $1: 1$ clove and ginger powders $(2.5 \mathrm{~g} /$ $100 \mathrm{~g}$ diet ), (cinnamon + clove + ginger $2.5 \mathrm{~g}$ ) diabetic rats fed on basal diet containing a mixture of cinnamon, clove and ginger powders by ratio of $1: 1: 1$ (2.5 g /100 g diet), (cinnamon $0.9 \%$ ) diabetic rats fed on basal diet containing cinnamon essential oil $(0.9 \mathrm{~g} / 100 \mathrm{~g}$ oil ),(clove $0.9 \%$ ) diabetic rats fed on basal diet containing clove essential oil (0.9 $\mathrm{g} / 100 \mathrm{~g}$ oil), (ginger $0.9 \%$ ) diabetic rats fed on basal diet containing ginger essential oil $(0.9 \mathrm{~g} / 100 \mathrm{~g}$ oil ), (cinnamon + clove $0.9 \%$ ) diabetic rats fed on basal diet containing a mixture of $1: 1$ cinnamon and clove essential oils ( $0.9 \mathrm{~g} / 100 \mathrm{~g}$ oil), (cinnamon + ginger $0.9 \%$ ) diabetic rats fed on basal diet containing a mixture of $1: 1$ cinnamon and ginger essential oils ( $0.9 \mathrm{~g} / 100 \mathrm{~g}$ oil), (clove + ginger $0.9 \%$ ) diabetic rats fed on basal diet containing a mixture of $1: 1$ clove and ginger essential oils ( 0.9 $\mathrm{g} / 100 \mathrm{~g}$ oil), (cinnamon + clove + ginger $0.9 \%$ ) diabetic rats fed on basal diet containing a mixture of $1: 1: 1$ cinnamon, clove and ginger essential oils ( $0.9 \mathrm{~g} / 100 \mathrm{~g}$ oil) Badee et al (2005b).

\section{Biochemical parameters}

Growth of rats: The rats were weighed twice weekly; total feed intake of each rat was weighed and feed conversion efficiency, (gain of rat weigh / total feed intake, g) was calculated. At the end of the experimental period, rats were weighed and killed.
Biochemical assay: At the end of experimental period, blood samples were collected from the animals from the eye plexuses on ice. Each sample was collected into both heparinized tubes to obtain the plasma and into a dry clean centrifuge glass tube without any coagulant to prepare serum. Blood was left for $15 \mathrm{~min}$ at room temperature, then the tubes were centrifuged for $15 \mathrm{~min}$ at $3000 \mathrm{rpm}$ and the clean supernatant serum was kept frozen at $-20^{\circ} \mathrm{C}$ until the time of analysis. Serum glucose and insulin were determined by Trinder (1969) and Temple et al (1992), respectively. Total cholesterol (TC.), high density lipoprotein (HDL), low density lipoprotein (LDL), VLDL- cholesterol and triglycerides (TG.) in serum were determined by using the methods described by Waston (1960); Assmann (1979); Wieland and Seidel (1983); Wallach (1992) and Fossati and Prencipe (1982), respectively. Liver function in serum: Alanine aminotransferase (ALT) and aspartate aminotransferase (AST) activities were assayed by the method of Bergmeyer and Harder (1986). Alkaline phosphatase (ALP) activity was measured using the method of Varley et al (1980). Kidney function in serum: Creatinine was measured using the method of Henry (1974) and urea was measured using the method of Fawcett and Scott (1960). The lipid peroxidation level (Malondialdehyde, MDA) in serum was determined by the colorimetric method described by Meltzer et al (1997). Total reduced glutathione (GSH) in erythrocytes and glutathione peroxidase activity in blood (GSPX) were measured calorimetrically according to the method of Ellman (1959) and Rotruck et al (1973), respectively.

Histopathological examination: Samples from the liver, kidneys, pancreas and heart were collected from rats in all groups at the end of experiments (60 days), fixed in 10\% neutral buffered formalin, dehydrated in alcohol, cleared in xylol and embedded in paraffin. Thick sections $(4 \mu)$ were prepared and stained with Hematoxylene and Eosin (Yoon et al 2001).

Statistical analysis: The obtained results were subjected to statistical analysis using the standard analysis of variance as outlined by Snedecor and Cochran (1980).

\section{RESULTS}

Data presented in Table (1) show that initial body weights did not significantly differ among the 
groups and at the end of experiment, regardless of the diet variation, there was increased significant differences among all the tested rat groups, except in case of the (P. control) diabetic which was significantly decreased (34.72\%) in food consumption and also decreased (49.36\%) in body weight comparing to non-diabetic control group. Spices or their essential oils and mixtures increased food consumption insignificantly and increased the body weight in diabetic rats. The same Table shows no significant differences in brain \%, among all the tested rat groups and the significant differences in the corresponding records, calculated as \% of the final weight, that was due to the significant variations in rat weights. The variances in weights of experimental rat organs are also monitored for indirect diabetes diagnosis and it was reported that the weights of the liver, kidney, heart and spleen were increased in diabetic rats. On contrary, there were no significant differences in liver, kidney, heart and spleen weights of the tested rat groups.

Table (2) displays the levels of serum glucose and insulin hormone in normal and experimental animals. The data revealed a significant increased elevation (222.83\%) in blood glucose and a significant decline in insulin levels $(41.61 \%)$ in (P. control) diabetic rats compared to (N. control) normal rats. Supplemented administration of diamicron30MR; cinnamon, clove and ginger spices or their essential oils and mixtures to diabetic rats significantly decreased the level of blood glucose and significantly increased the level of insulin compared to (P. control) control diabetic group.

Table 2. Effect of cinnamon, clove and ginger powders and their essential oils on serum glucose and insulin concentrations in experimental diabetic rats

\begin{tabular}{|c|c|c|}
\hline Treatments & $\begin{array}{c}\text { Glucose } \\
\text { (mg/dl) }\end{array}$ & $\begin{array}{l}\text { Insulin } \\
(\mu \mathrm{IU} / \mathrm{mI})\end{array}$ \\
\hline N. control & $83.17^{f} \pm 0.098$ & $46.62^{\mathrm{a}} \pm 0.716$ \\
\hline P. control & $268.50^{a} \pm 0.318$ & $27.22^{\mathrm{e}} \pm 0.508$ \\
\hline Diamicron & $118.00^{d} \pm 0.196$ & $39.65^{b} \pm 0.375$ \\
\hline \multicolumn{3}{|c|}{ Powders } \\
\hline Cinnamon $(2.5 \mathrm{~g})$ & $150.25^{c} \pm 0.289$ & $30.82^{c} \pm 0.473$ \\
\hline Clove $(2.5 \mathrm{~g})$ & $150.29^{c} \pm 0.167$ & $30.62^{c} \pm 0.117$ \\
\hline Ginger $(2.5 \mathrm{~g})$ & $150.58^{c} \pm 0.162$ & $31.19^{c} \pm 0.687$ \\
\hline Cinnamon+ Clove $(2.5 \mathrm{~g})$ & $150.67^{c} \pm 0.387$ & $30.61^{c} \pm 0.352$ \\
\hline Cinnamon+ Ginger (2.5g) & $150.24^{c} \pm 0.139$ & $31.21^{c} \pm 0.109$ \\
\hline Clove+ Ginger (2.5g) & $150.93^{c} \pm 0.537$ & $30.92^{c} \pm 0.531$ \\
\hline Cinnamon+ Clove+ Ginger (2.5g) & $158.78^{b} \pm 0.450$ & $28.91^{d} \pm 0.121$ \\
\hline \multicolumn{3}{|c|}{ Essential oils } \\
\hline Cinnamon $(0.9 \%)$ & $117.50^{\text {de }} \pm 0.635$ & $39.80^{b} \pm 0.260$ \\
\hline Clove $(0.9 \%)$ & $117.67^{\text {de }} \pm 0.387$ & $40.00^{b} \pm 0.312$ \\
\hline Ginger (0.9\%) & $117.36^{\text {de }} \pm 0.370$ & $39.86^{b} \pm 0.497$ \\
\hline Cinnamon+ Clove (0.9\%) & $117.65^{\text {de }} \pm 0.953$ & $39.98^{b} \pm 0.393$ \\
\hline Cinnamon+ Ginger (0.9\%) & 117.20 de \pm 0.231 & $40.17^{b} \pm 0.098$ \\
\hline Clove+ Ginger (0.9\%) & $117.65^{\text {de }} \pm 0.260$ & $39.86^{b} \pm 0.497$ \\
\hline Cinnamon+ Clove+ Ginger (0.9\%) & $116.90^{e} \pm 0.266$ & $40.67^{b} \pm 0.231$ \\
\hline \multicolumn{3}{|c|}{ LSD } \\
\hline & 1.057 & 1.098 \\
\hline
\end{tabular}

- Means, within the same column, followed by the same letter are not significantly different at $<0.05$.

- Means are followed by the corresponding standard deviation. 
The oxidation stress (STZ) significantly increased serum total cholesterol (TC), low-density lipoprotein- cholesterol (LDL-C), triglycerides (TG) and very low- density lipoprotein-cholesterol (VLDL - C) .While HDL- cholesterol was significantly decreased, as shown in Table (3). Administration of the tested antioxidants improved or returned these values to the normal ones.

Administration of STZ produced significantly adverse effects on the liver functions and kidney functions of the rats, which are evidenced by a significant increase in the activities of ALT, AST and ALP enzymes and kidney functions (ceatinine and urea) as compared with normal (Table 4). Treatment of diabetic rats with cinnamon, clove and ginger spices or their essential oils and mixtures exhibited improvement in liver and kidney functions compared to diabetic rats.

Table (5) show the levels of malonaldehyde (MDA), GSH-Px activity and reduced GSH in normal and experimental rat groups. The maloaldehyde (MDA) was significantly increased, while the activity of GSH-Px and reduced GSH were significantly decreased in (P. control) diabetic rats, when compared with the (N. control) normal group. Supplementation of the experimental diabetic rat groups with cinnamon, clove and ginger powders or their essential oils and mixtures extracts increased the GSH-Px activity and reduced GSH level in blood.

Figure (1) showed the microscopic examination of the liver of the tested rat groups. N. control (untreated rat group) revealed a normal histological structure of hepatic lobule (Slide 1). Meanwhile, the liver of rat from p. control (diabetic group) showed kupffer cells activation, necrosis of sporadic hepatocytes as well as simusoidal leucocytosis (Slide 2). However the liver of diabetic rat treated with diamicron30MR showed hydropic degeneration of hepatocytes as well as simusoidal leucocytosis (Slide 3 ) in addition to congestion of hepatoportal blood vessels and edema in the portal triad in some examined sections. While, the liver of rat from group [cinnamon $2.5 \mathrm{~g}$ and cinnamon + ginger $(2.5 \mathrm{~g})]$ showed vacuolization of some hepatocytes (Slide 4). Moreover, the liver of rat from group (clove $2.5 \mathrm{~g}$ ) showed hydropic degeneration of hepatocytes and simusoidal leucocytosis (Slide 5). Whereas, the liver of rat from group (ginger $2.5 \mathrm{~g}$ ) showed, slight kupffer cells activation (Slide 6). Hydropic degeneration of some hepatocytes as well as necrosis of sporadic hepatocytes (Slide 7) was observed in liver of rat from group [cinnamon + clove $(2.5 \mathrm{~g})$ and clove + ginger $(2.5 \mathrm{~g})$ ]. Mean- while, the liver of rat from group [cinnamon + clove + ginger $(2.5 \mathrm{~g})$ ] showed vacuolization of hepatocytes (Slide 8 ). In addition, the liver of rat from all groups fed on all essential oils showed no changes with apparent normal hepatocytes. On the other hand, Figure (1) showed also the microscopic examination of the kidney of the tested rat groups. N. control (untreated rat group) revealed a normal histological structure (Slide 9). Meanwhile, the kidney of rat from p. control (diabetic group) showed vacuolation of epithelial lining renal tubules (Slide 10), dilatation and congestion of renal blood vessels associated with hypertrophy of glomerular tufts (Slide 11) were noticed in examined sections of kidneys from diabetic rat. However, the kidney of diabetic rat treated with diamicron30MR showed granularity of epithelial lining renal tubules as well as atrophy of some glomerular tufts (Slide 12), revealed vacuolations of epithelial lining some renal tubules associated with pyknosis of some nuclei (Slide 13). The kidney of rat from groups [cinnamon $2.5 \mathrm{~g}$, clove $2.5 \mathrm{~g}$, ginger $2.5 \mathrm{~g}$, cinnamon + clove $(2.5 \mathrm{~g})$, cinnamon +ginger $(2.5 \mathrm{~g})$ and clove+ ginger(2.5g)] showed congestion of renal blood vessels (Slide 14).Meanwhile, the kidney of rat from group [cinnamon + clove + ginger (2.5g)] showed vacuolations of epithelial lining renal tubules (Slide 15), dilatation and congestion of renal blood vessels (Slide 16). In addition, the kidney of rat from all groups fed on all essential oils showed no changes with apparent normal histological structure.

Figure (2) showed the microscopic examination of the pancreas of the tested rat groups. N. control (untreated rat group) revealed a normal histological structure (Slide 1). Meanwhile, the pancreas of rat from $p$. control (diabetic group) showed a focal pancreatic hemorrhage (Slide 2), cystic dilatation of pancreatic duct and atrophy of langerhan's islet's (Slide 3). However, pancreas of diabetic rat treated with diamicron30MR showed vacular degeneration of epithelial lining pancreatic acini (Slides 4 and 5).While, pancreas of rat from groups [cinnamon $2.5 \mathrm{~g}$, clove $2.5 \mathrm{~g}$, ginger $2.5 \mathrm{~g}$, cinnamon + clove $(2.5 \mathrm{~g})$, cinnamon +ginger $(2.5 \mathrm{~g})$ and clove+ ginger(2.5g)] showed vacular degeneration of epithelial lining some pancreatic acini (Slide 6).Meanwhile, the pancreas of rat from group [cinnamon + clove + ginger $(2.5 \mathrm{~g})$ ] showed cystic dilatation of pancreatic duct (Slide 7) and hyperplasia of $B$ cells of langerhan's islet's (Slide 8). In addition, the pancreas of rat from all groups fed on all essential oils showed no changes with apparent normal histological structure. In addition, 
Arab Univ. J. Agric. Sci., 18(1), 2010 
Table 5. Effect of cinnamon, clove and ginger powders and their essential oils on the activity levels of glutathione peroxidase, reduced glutathione and TBARS concentrations in experimental diabetic rats

\begin{tabular}{|c|c|c|c|}
\hline Treatments & $\begin{array}{l}\text { TBARS } \\
\text { (mg/dl) }\end{array}$ & $\begin{array}{c}\text { GSH } \\
(\mathrm{mg} / \mathrm{dl})\end{array}$ & $\begin{array}{l}\text { GSPX } \\
(\mathrm{U} / \mathrm{ml})\end{array}$ \\
\hline N. control & $0.576^{e} \pm 0.044$ & $40.85^{\mathrm{a}} \pm 0.491$ & $170.80^{a} \pm 0.450$ \\
\hline P. control & $2.875^{\mathrm{a}} \pm 0.043$ & $19.77^{d} \pm 0.431$ & $85.49^{\mathrm{e}} \pm 0.860$ \\
\hline Diamicron & $0.972^{d} \pm 0.013$ & $33.37^{b} \pm 0.214$ & $136.65^{b} \pm 0.173$ \\
\hline \multicolumn{4}{|c|}{ Powders } \\
\hline Cinnamon $(2.5 \mathrm{~g})$ & $1.323^{c} \pm 0.013$ & $25.63^{c} \pm 0.364$ & $109.39^{c} \pm 0.225$ \\
\hline Clove $(2.5 \mathrm{~g})$ & $1.316^{c} \pm 0.009$ & $25.50^{c} \pm 0.289$ & $109.65^{c} \pm 0.375$ \\
\hline Ginger $(2.5 \mathrm{~g})$ & $1.289^{c} \pm 0.011$ & $25.80^{c} \pm 0.279$ & $109.87^{c} \pm 0.502$ \\
\hline Cinnamon+ Clove $(2.5 \mathrm{~g})$ & $1.316^{c} \pm 0.008$ & $25.60^{c} \pm 0.208$ & $109.74^{\mathrm{c}} \pm 0.427$ \\
\hline Cinnamon+ Ginger $(2.5 \mathrm{~g})$ & $1.286^{c} \pm 0.050$ & $25.66^{c} \pm 0.393$ & $109.76^{c} \pm 0.439$ \\
\hline Clove+ Ginger (2.5g) & $1.297^{c} \pm 0.016$ & $25.19^{c} \pm 0.687$ & $109.40^{c} \pm 0.231$ \\
\hline Cinnamon+ Clove+ Ginger (2.5g) & $1.537^{b} \pm 0.021$ & $25.66^{c} \pm 0.266$ & $103.72^{d} \pm 0.416$ \\
\hline \multicolumn{4}{|c|}{ Essential oils } \\
\hline Cinnamon $(0.9 \%)$ & $0.986^{d} \pm 0.038$ & $33.86^{b} \pm 0.497$ & $137.17^{b} \pm 0.346$ \\
\hline Clove $(0.9 \%)$ & $0.968^{d} \pm 0.039$ & $33.95^{b} \pm 0.548$ & $137.00^{b} \pm 0.537$ \\
\hline Ginger (0.9\%) & $0.984^{d} \pm 0.048$ & $33.67^{b} \pm 0.387$ & $136.78^{b} \pm 0.450$ \\
\hline Cinnamon+ Clove $(0.9 \%)$ & $0.962^{d} \pm 0.007$ & $33.49^{b} \pm 0.283$ & $136.85^{b} \pm 0.491$ \\
\hline Cinnamon+ Ginger (0.9\%) & $0.958^{d} \pm 0.010$ & $33.96^{b} \pm 0.554$ & $137.00^{b} \pm 0.266$ \\
\hline Clove+ Ginger (0.9\%) & $0.965^{d} \pm 0.009$ & $33.70^{\mathrm{b}} \pm 0.404$ & $136.80^{b} \pm 0.115$ \\
\hline Cinnamon+ Clove+ Ginger (0.9\%) & $0.945^{d} \pm 0.026$ & $34.00^{b} \pm 0.202$ & $137.48^{\mathrm{b}} \pm 0.155$ \\
\hline \multicolumn{4}{|c|}{ LSD } \\
\hline & 0.05259 & 0.7419 & 1.002 \\
\hline
\end{tabular}

\footnotetext{
- Means, within the same column, followed by the same letter are not significantly different at $<0.05$.

- Means are followed by the corresponding standard deviation.
}

Figure (2) showed the microscopic examination of the heart of the tested groups. N. control (untreated rat group) showed apparent normal cardiac muscle fibers with no histopathological changes (Slide 9). Meanwhile, the heart of rat from p. control (diabetic group) showed vacuolation of some cardiac muscles fibers and granularity of other muscle fibers (Slide 10) and zenker's necrosis of sporadic muscle fibers associated with intermuscular edema (Slide11). However, the heart of diabetic rat treated with diamicron30MR showed zenker's necrosis of sporadic muscle fibers (Slides12) and intermuscular edema (Slide13).While, the heart of rat from group [cinnamon $2.5 \mathrm{~g}$, clove $2.5 \mathrm{~g}$, ginger $2.5 \mathrm{~g}$, cinnamon + clove $(2.5 \mathrm{~g})$, cinnamon +ginger $(2.5 \mathrm{~g})$ and clove+ ginger(2.5g)] showed no changes except vacuolations of sporadic cardiac muscles fibers (Slide14). Meanwhile, the heart of rat from group [cinnamon + clove + ginger (2.5g)] showed marked dilatation and congestion of cardiac blood vessels (Slide15) and zenker's necrosis of sporadic muscle fibers (Slide 16). In addition, the heart of rat from all groups fed on all essential oils showed apparent normal cardiac mucle fibers with no histological changes. 


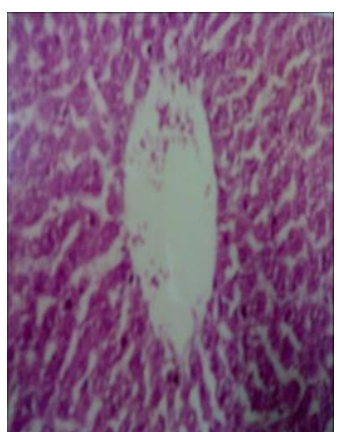

Slide (1): N. Control group liver

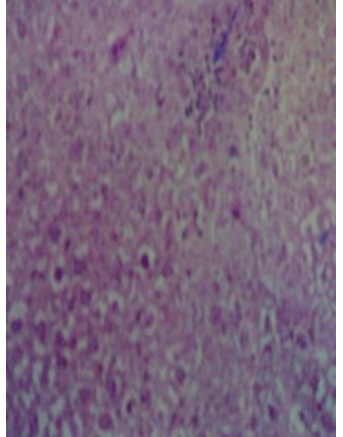

Slide (3): Diamicron group, liver

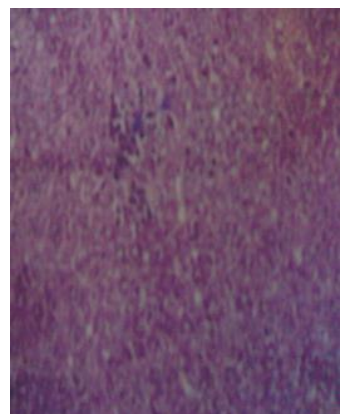

Slide (5): clove $2.5 \mathrm{~g}$ group, liver

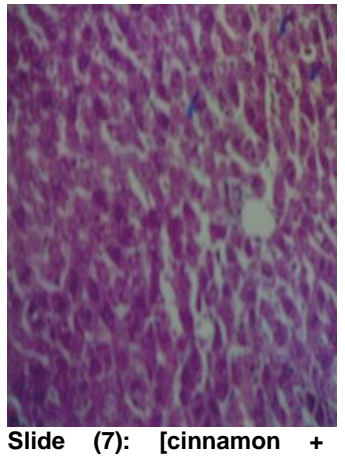

clove $(2.5 \mathrm{~g})$ and clove + ginger $(2.5 \mathrm{~g})]$ groups ,liver

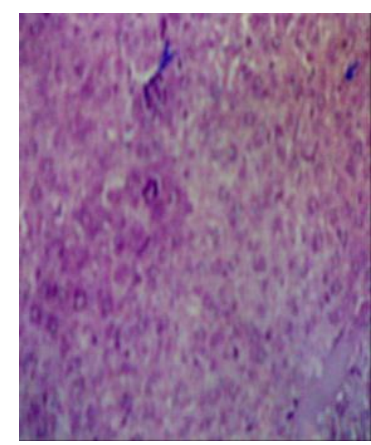

Slide (2): P. Control group, liver

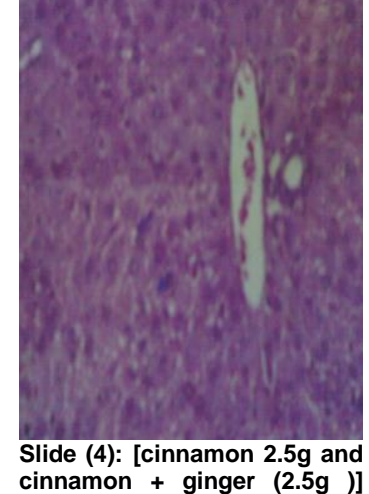
groups, liver

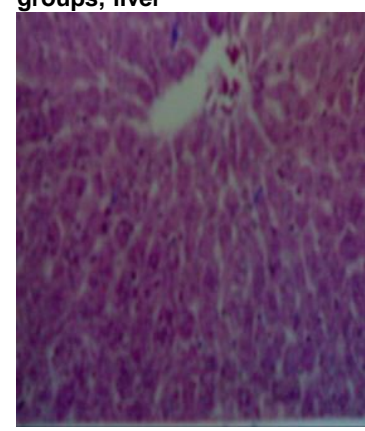

Slide (6): ginger $2.5 \mathrm{~g}$ group, liver

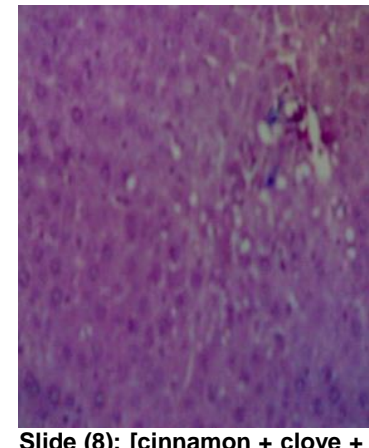

ginger (2.5g)] group, liver

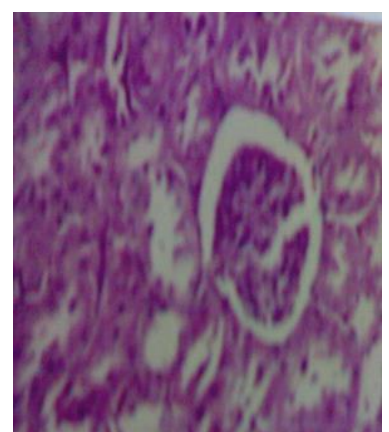

Slide (9): N. Control group, kidney

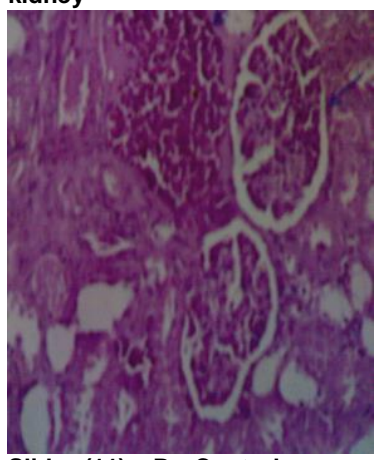

Slide (11): P. Control group, kidney

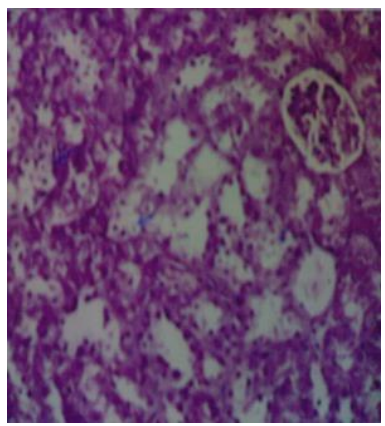

Slide (13): Diamicron group, kidney

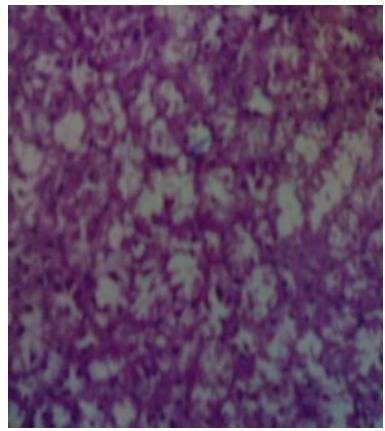

Slide (15): [cinnamon + clove + ginger $(2.5 \mathrm{~g})]$ group ,kidney

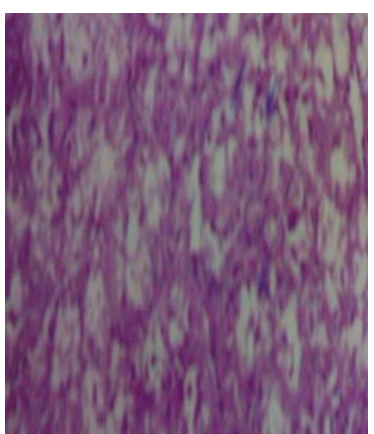

Slide (10): P. Control group, kidney

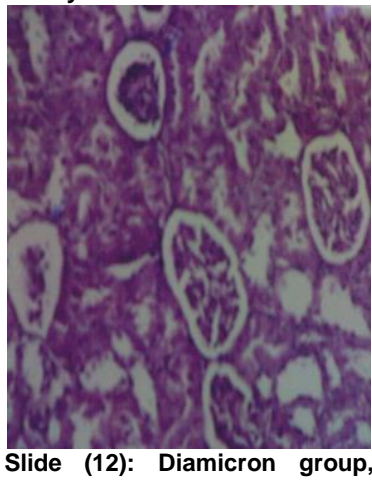
kidney

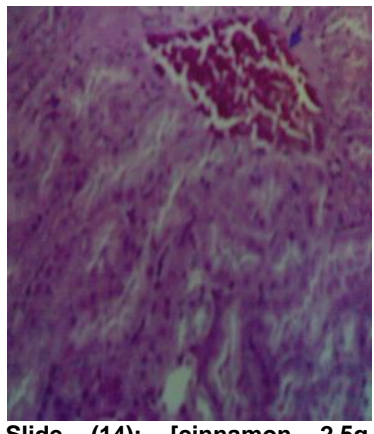

Slide (14): [cinnamon 2.5g, clove $2.5 \mathrm{~g}$, ginger $2.5 \mathrm{~g}$, cinnamon + clove $(2.5 \mathrm{~g})$, cinnamon +ginger $(2.5 \mathrm{~g})$ and clove+ ginger $(2.5 \mathrm{~g})]$ groups, kidney

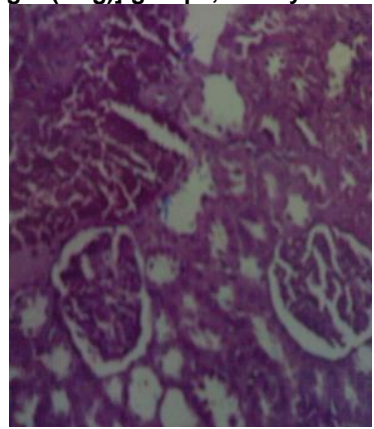

Slide (16): [cinnamon + clove + ginger $(2.5 \mathrm{~g})]$ group, kidney

Figure 1. Histopathological changes in sections of liver and kidney 


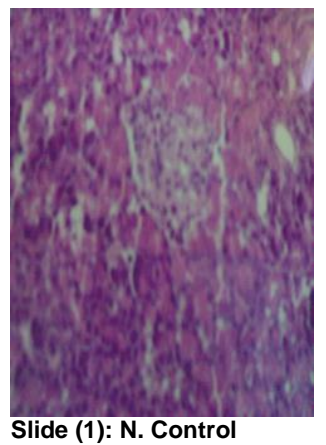

Slide (1): N. Control

group, pancreas

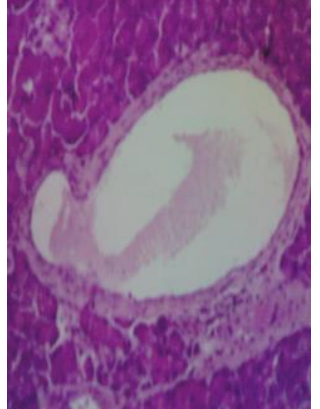

Slide (3): P. Control

group, pancreas

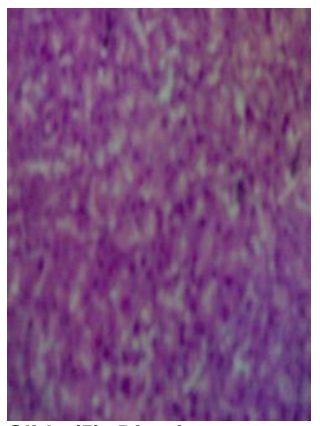

Slide (5): Diamicron group, pancreas

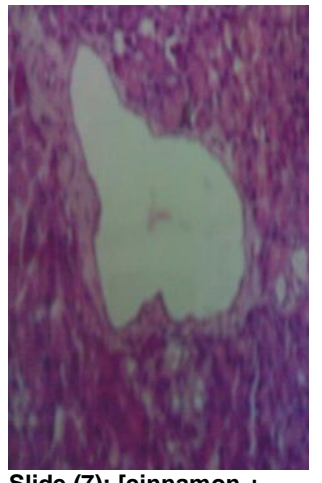

Slide (7): [cinnamon + clove + ginger $(2.5 \mathrm{~g})$ group, pancreas

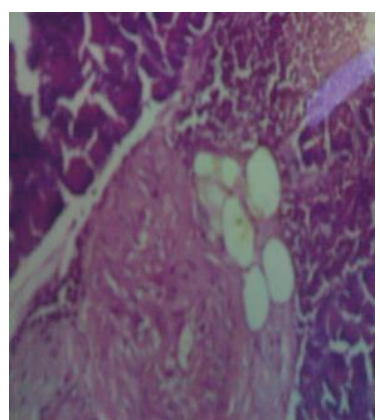

Slide (2): P. Control group ,pancreas

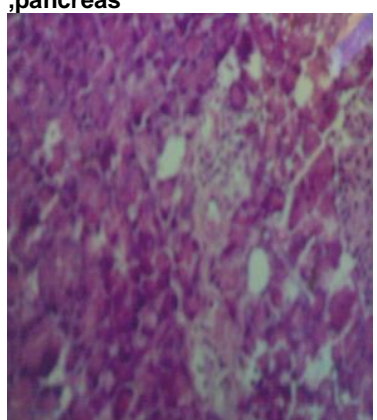

Slide (4): Diamicron group

,pancreas

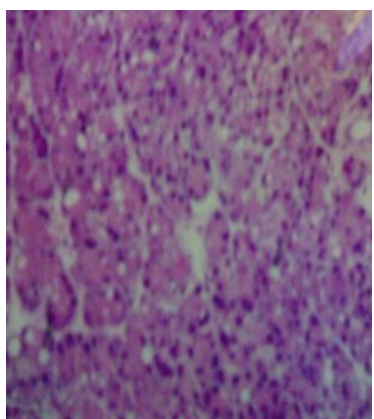

Slide (6): [cinnamon $2.5 \mathrm{~g}$, clove $2.5 \mathrm{~g}$, ginger $2.5 \mathrm{~g}$, cinnamon + clove $(2.5 \mathrm{~g})$, cinnamon +ginger $(2.5 \mathrm{~g})$ and clove+ ginger( $2.5 \mathrm{~g})$ ] groups, pancreas

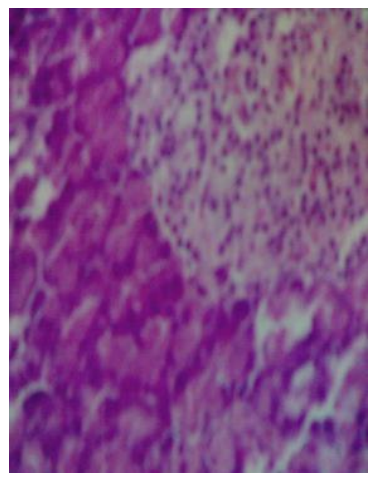

Slide (8): [cinnamon + clove + ginger $(2.5 \mathrm{~g})]$ group, pancreas

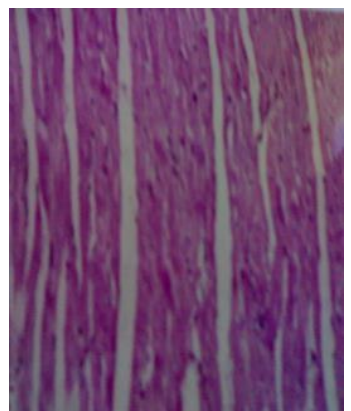

Slide (9): N. Control group, heart

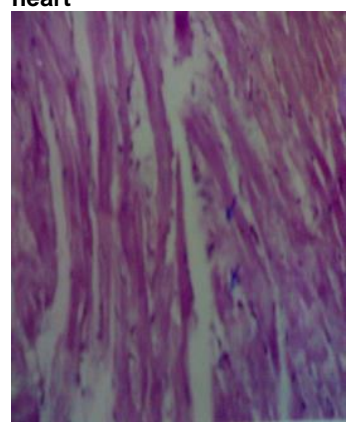

Slide (11): P. Control group, heart

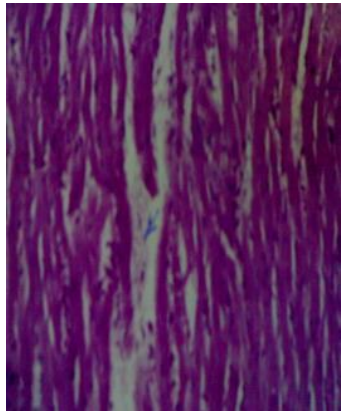

Slide (13): Diamicron group, heart

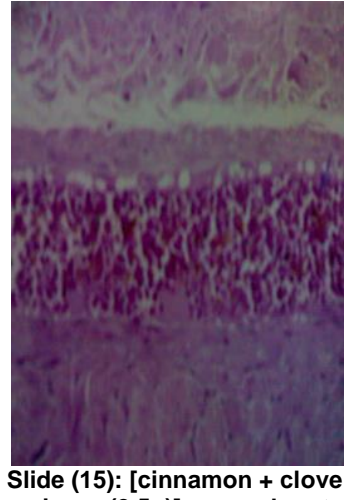
+ ginger $(2.5 \mathrm{~g})$ ] group, heart

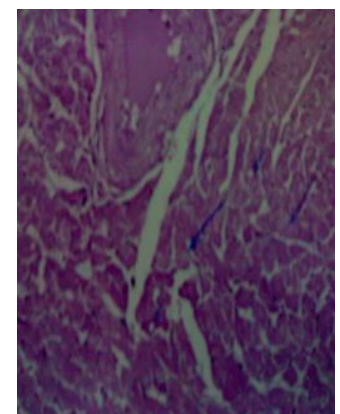

Slide (10): P. Control group heart

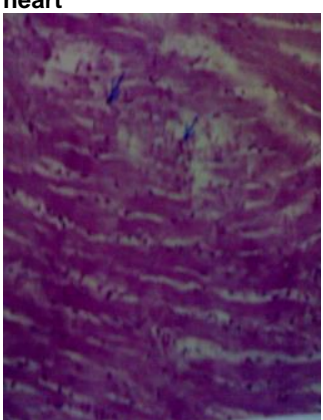

Slide (12): Diamicron group heart

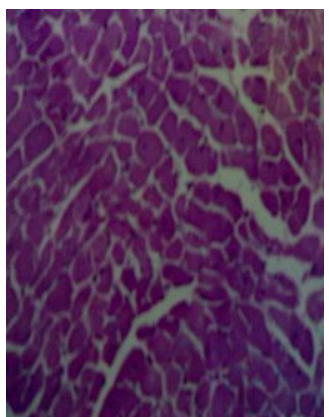

Slide (14): [cinnamon $2.5 \mathrm{~g}$

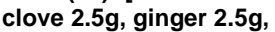
cinnamon + clove $(2.5 \mathrm{~g})$ cinnamon +ginger $(2.5 \mathrm{~g})$ and clove+ ginger $(2.5 \mathrm{~g})$

groups, heart

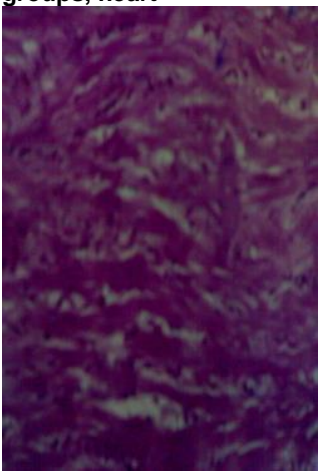

Slide (16): [cinnamon + clove + ginger $(2.5 \mathrm{~g})]$ group heart

Figure 2. Histopathological changes in sections of pancreas and heart

Arab Univ. J. Agric. Sci., 18(1), 2010 


\section{DISCUSSION}

Diabetes is a chronic metabolic disorder affecting a major proportion of the population worldwide. A sustained reduction in hyperglycemia will decrease the risk of developing microvascular diseases and reduce their complications (Kim et al 2006). The conventional therapies for diabetes have many shortcomings like side effects and high rate of secondary failure. On the other hand, spices extracts are expected to have similar efficacy without side effects as that of conventional drugs. The present investigation reports the antidiabetogenic and hypoglycemic effects of diamicron30MR and essential oils on STZ induced diabetic rats. STZ injection resulted in diabetes mellitus, which is probably due to the destruction of $\beta$ cells of islets of Langerhans as proposed by many authors (Maiti et al 2004; Maiti et al 2005 and Beppu et al 2006).

Diabetic rats showed a significant decrease in body weight compared to control rats. Decreased body weight observed in diabetic rats is due to excessive breakdown of tissue proteins (Ravi et al 2004b). These results are in accordance with the present results previously as shown in streptozotocin-induced diabetic rats (Yanardag et al 2003). In our study, administration of spices and their essential oils for 60 days caused an increase in body weights in the diabetic groups (Darias et al 2001 and Ozsoy -Sacan 2006).

Oxidative free radicals have been implicated in the pathogenesis of diabetes mellitus. In addition, diabetic patients have significant defects of antioxidant protection, and it is believed that the metabolic disorders in diabetes mellitus may be due to increasing cellular oxidative stress and reduced antioxidant protection. The antidiabetic action of spices seems to be mediated through; stimulation of the pancreas to produce and recreate insulin, interference with dietary glucose absorption and insulin sparing action of the constituent bioactive compounds (Srinivasan, 2005 and Saravanan \& Pari, 2008). In other study, noted that some essential oil extract decreased blood glucose levels by facilitating glucose usage via extra-pancreatic ways (Subash Babu et al 2007; Hassan et al 2009 and Zari \& Al-Logmani, 2009).

The present study showed that there were higher levels of cholesterol and triglycerides in STZ induced-diabetic rats. The level of lipids is usually raised in diabetes and such an elevation represents a risk factor for coronary heart disease (Pacheco et al 2001). The abnormal high concen- tration of lipids in diabetes are mainly due to an increase in adipose tissue lipolysis in absence of insulin and mobilization of free fatty acids from the peripheral depots, since insulin inhibits the hormone sensitive lipase. On the other hand, glucagon, catecholamines and other hormones enhance lipolysis. The marked hyperlipidamia that characterizes the diabetic state may therefore be regarded as a consequence of the uninhibited actions of lipolytic hormones on the fat depots (Akula et al 2003 and Pruneta-Deloche et al 2004). STZinduced diabetus mellitus increases oxidative stress and the presence of oxidized LDLcholesterol and other lipoproteins. Oxidation converts LDL-cholesterol to a form that is rapidly taken up and degraded by macrophages and increased degradation of unoxidized LDL-cholesterol. Oxidized lipoproteins play an important role in the development of atherosclerosis (Jafarnejad et al 2008). The results of the study under investigation show that continuous administration of the essential oils of cinnamon, clove and ginger prevent elevation of serum lipids (Badee et al 2005b). The hypolipidaemic effect can be explained as a direct reduction in blood glucose concentration, lowering cholesterol and triglycerides could also be probably attributed to regenerate pancreatic $B$-cells and by decreasing 3-hydroxyl-3-methylglutaryl coenzyme A reductase (HMG-CoA reductase activity), a key enzyme of cholesterol biosynthesis and/or by reducing the NADPH required for fatty acids and cholesterol biosynthesis (Sharma et al 2003; Vessal et al 2003 and Srinivasan et al 2005) or the extract might stimulate the production of insulin which in turn inhibits lipoprotein lipase activity (Ravi et al 2005). Antioxidants inhibit metabolism of LDL-cholesterol and reduce toxicity of oxidized LDL-cholesterol (Ravi et al 2004a).

Liver function could detect the state of liver. Liver Function Tests (LFTS) are commonly used in clinical practice to screen for liver disease, monitor the progression of known disease, monitor the effects of potentially hepatotoxic drugs and necrosis in the liver of animals. The most common LFTS include the serum aminotransferases, alkaline phosphatase, bilirubin, albumin and prothrombin time Harris (2005). Aminotransferases such as alanine aminotransferase (ALT) and aspartate aminotrasferase (AST) measure the concentration of intracellular hepatic enzymes that have leaked into the circulation and serve as a maker of hepatocyte injury. Moreover, ALT and AST levels also act as indicators of liver function and restoration of normal levels of these parameters indicate 
normal functioning of liver. The increased gluconeogenesis and ketogenesis observed in diabetes may be due to high level in the activities of these transaminases (McAuff et al 2003). Moreover, Ozlem et al (2006) and Subash Babu et al (2007) who mentioned that in STZ-induced diabetic rats, the activity of serum ALP was significantly increased which supporting our findings. Therefore, the increase of the activity ALP in serum is mainly due to the leakage of the enzymes from the liver cytosol into the blood stream (Mansour et al 2002), which gives an indication on the hepatotoxic effect of streptozotocin. On the other hand, the administration of some essential oil extract to STZinduced diabetic rats reduced ALP activity towards its normal values. The increase in ALP activity in serum is an indicator of liver destruction .In our study, the decrease in ALP activity in STZ-induced diabetic rats given essential oils extract shows that essential oils prevented liver damage.Generally, the serum ALT , AST and ALP levels increase as a result of metabolic changes in the liver, such as administration of toxin, cirrhosis of the liver, hepatitis, and liver cancer (Chalasani et al 2004 and Hwang et al 2005). Thus, they can be used as markers to assess the extent of liver damage.

Histopathological study of liver showed fatty changes surrounding portal triad in the liver of diabetic rats and the treatment with spices or their essential oils recovered the membrane damage by decreasing lipid peroxidation and improving antioxidants' status which was reported earlier by us (Ramesh and Pugalendi 2006a).

Creatinine is the major waste product of creatine metabolism. In the kidney, it is filtered by the glomerulus and actively excreted by the tubules. Moreover, free creatinine appears in the blood serum (Foley et al 2005; Myers et al 2006 and Stevenes et al 2006), urea is the principal waste products of protein catabolism. They synthesized in the liver from ammonia produced as a result of the deamination of amino acids. The rate of production is accelerated by a high protein diet or by increased endogenous catabolism due to starvation or tissue damage (Bequette and Sunny 2005). Kidney function tests help to determine if the kidney is performing their task adequately. The diabetic rats had increased levels of creatinine and urea which are considered as significant markers of renal function and this is in agreement with the present result (Ozsoy-Sacan et al 2006). The kidneys of rats with streptozotocin-induced diabetes become enlarged (Ramesh et al 2007). Histopathological studies of kidney showed enlargement of lining cells of tubules, fatty infiltration, large area of hemorrhage and lymphocyte infiltration in the diabetic rats, which may be associated with membrane damage caused by hyperglycemia mediated oxidative stress and altered fatty acid composition and treatment with essential oils reversed these changes to near normalcy, which could be associated with decreased membrane damage as evidenced by improved antioxidants status (Ramesh and Pugalendi 2006a), reversed fatty acid changes as evidenced by improved insulin level (Ramesh and Pugalendi, 2005), and also supported by regulated glycoprotein components (Ramesh and Pugalendi 2006b).

Oxidative stress plays an important role in chronic complications of diabetes and is postulated to be associated with increased lipid peroxidation (Murugan and Pari 2007). Streptozotocin is frequently used to induce diabetes mellitus in experimental animals through its toxic effects on pancreatic B-cells (Kim et al 2003). The cytotoxic action of STZ is associated with the generation of reactive oxygen species causing oxidative damage (Szkudelski, 2001).The increased free radicals produced may react with polyunsaturated fatty acids in cell membranes leading to lipid peroxidation. Lipid peroxide-mediated damage has been observed in the development of diabetes (Anwer et al 2007). The most commonly used indicator of lipid peroxidation is TBARS. The increased lipid peroxidation in the serum of diabetic animals may be due to the observed remarkable increase in the concentration of free radical in the serum of diabetic rats. In the current study, level of serum TBARS in diabetic rats groups supplemented with essential oils extractions showed a significant reduction which indicates a decreased rate of lipid peroxidation (Afshari et al 2007).

Concerning to the changes in lipid peroxidation, the serum diabetic showed decreased the concentration of the key antioxidants reduced GSH and activity of GSH-Px which play an important role in scavenging the toxic intermediate of incomplete oxidation. The decrease in the activity of these antioxidants can lead to an excess availability of the superoxide anion $\left(\mathrm{O}_{2}^{-}\right)$and hydrogen peroxide in biological system, which generate hydroxyl radicals resulting in initiation and propagation of lipid peroxidation. Administration of diabetic rats with essential oils extraction increased the activity of enzymes and may help to control free radicals (Lee 2006).

GSH plays a central role in antioxidant defense by detoxifying reactive oxygen species, directly or 
in a glutathione peroxidase catalyzed mechanism. and in the repair of radically caused biological damage (Ananthan et al 2004), and its level reduced in diabetes mellitus (Latha and Pari 2003). The decrease in GSH levels represents increased utilization due to oxidative stress (Venkateswaran and Pari 2003). The elevated level of GSH protects cellular proteins against oxidation through the glutathione redox cycle and also directly detoxifies reactive oxygen species generated from exposure to STZ (Latha and Pari 2003).

The GSH content increment in the serum of rats treated with essential oils extractions. Essential oils can be directly scavenging the free radicals in diabetic rats, may reduce the utilization of GSH and thereby exhibiting an increase in the GSH content in treated diabetic rats (Ozsoy-Sacan et al 2006). Furthermore, insufficient availability of GSH may also reduce the activity of GSH-PX (Anwer et al 2007). The GSH content increment in the serum of rats treated with essential oils extractions may be a responsible factor for inhibition of lipid peroxidation. The elevated level of GSH protects cellular proteins against oxidation through glutathione redox cycle and also directly detoxifies reactive oxygen species.

In general, the present study concluded that the concentration of lipid peroxidation is a successful indicator to the increment of free radicals in the serum of diabetic rats. Consequently, administration of essential oils extracts (cinnamon, clove and ginger), significantly declined the levels of lipid peroxidation and thus prevent tissue damage.

The author thanks Dr. Kawkab Abd-EIAziz Ahmed from department of pathology, Faculty of Vet. Med., Cairo. Univ., for providing the explanation about histopathology.

\section{REFERENCES}

Afshari, A.T.; A. Shirpoor; A. Farshid; R. Saadatian; Y. Rasmi; E. Saboory; B. Ilkhanizadeh and A. Allameh (2007). The effect of ginger on diabetic nephropathy, plasma antioxidant capacity and lipid peroxidation in rats. Food Chemistry, 101: 148-153.

Ahmed, R.S.; V. Seth and B.D. Banerjee (2000). Influence of dietary ginger (Zingiber officinale Rosc) on antioxidant defense system in rat : comparison with ascorbic acid. Indian Journal of Experimental Biology, 38: 604-606.

Akula, A.; M.K. Kota; S.G. Gopisetty; R.V. Chitrapu; M. Kalagara; S. Kalagara; K.K. Veeravalli and J.P. Gomedhikama (2003). Biochemical, histological and echocardiographic changes during experimental cardiomyopathy in STZ-induced diabetic rats. Pharmacological Research, 48: 429435.

Alam, K.; S. Mahpara; M.A.K. Mohammad; N.K. Khan and A.A. Richard (2003). Cinnamon improves glucose and lipids of people with type 2 diabetes. Diabetes Care, 26: 3215-3218.

Al-Qattan, K.; M. Thomson and M. Ali (2008). Garlic (Allium sativum) and ginger (Zingiber officinale) attenuate structural nephropathy progression in streptozotocin-induced diabetic rats. Journal of Clinical Nutrition and Metabolism, 3: e62-e71.

Ananthan, R.; M. Latha; K.M. Ramkumar; L. Pari; C. Baskar and V. Narmatha Bai (2004). Modulatory effects of Gymnema montanum leaf extract on alloxan-induced oxidative stress in wistar rats. Nutrition, 20: 280-285.

Anwer, T.; M. Sharma; K.K. Pillai; S.E. Haquea; M.M. Alam and M.S. Zaman (2007). Protective effect of bezafibrate on streptozotocin-induced oxidative stress and toxicity in rats. Toxicology, 229: 165-172.

Assmann, G. (1979). A fully enzymatic colorimetric determination of HDL-cholesterol in the serum. Internist, 20: 559-565.

Badee, A.Z.M.; A.T.M. El-Akel; S.A.M. Hafez; Kawkab, A. Ahmed and N.H.M. Hassanen (2005a) . Flavoring and preservation of biscuits by using some spices. Proc. The Third International Conference for Food Science and Technology, Modernizing Food Industries, pp. 105-124, Cairo, Egypt.

Badee, A.Z.M.; A.T.M. El-Akel; S.A.M. Hafez; Kawkab, A. Ahmed and N.H.M. Hassanen (2005b). Biochemical and histopathological effects of cinnamon, clove and ginger powders and their essential oils. Proc. The Third International Conference for Food Science and Technology, Modernizing Food Industries, pp. 125-144, Cairo, Egypt.

Beppu, H.; K. Shimpo; T. Chihara; T. Kaneko; I. Tamai; S. Yamaji; S. Ozaki; H. Kuzuya and S. Sonoda (2006). Antidiabetic effects of dietary administration of Aloe arborescens Miller components in multiple low-dose streptozotocin-induced diabetes in mice: Investigation on hypoglycemic action and systemic absorption dynamics of aloe components. J. Ethnopharmacol, 103: 468-477.

Bequette, B.J. and N.E. Sunny (2005). Reading nitrogenexcretion in ruminants: the potential to increase urea recycling. Proc. of the 3 rd MildAtlantic Nutrition Confefence, pp. 123-133, Timonium, Maryland, USA. 
Bergmeyer, H.U. and M. Harder (1986). A colorimeteric method of determination of serum glutamic oxaloacetic and glutamic pyruvic transaminase. Clin. Biochem., 24: 28 - 34.

Broadhurst, C.L.; M.M. Polansky and R.A. Anderson (2000). Insulin-like biological activity of culinary and medicinal plant aqueous extracts in vitro. Journal of Agricultural and Food Chemistry, 48: 849-852.

Chalasani, N.; H. Aljadhey; J. Kesterson; M.D. Murray and S.D. Hall (2004). Patients with elevated liver enzymes are not at higher risk for statin hepatotoxicity. Gastroenterology,126: 1287-1292. Darias, V.; D. Martin-Herrera; S. Abdala and D. Fuente (2001). Plants used in urinary pathologies in the Canary islands. Pharmaceutical Biology, 39: 170-180.

Ellman, G.L. (1959). Tissue sulfhydrl groups. Archieves of Biochem. and Biophys., 82: 70-77. Fawcett, J.K. and J.E. Scott (1960). Enzymatic colorimetric method for determination urea in serum, plasma and urine. J. Clin. Path., 13: 156162.

Foley, R.N.; C. Wang and A.J. Collins (2005). Cardiovascular risk factor profiles and kidney function stage in the US general population: the NHANES III study. Mayo Clinic Proceedings, 80: 1270-1277.

Fossati, P. and L. Prencipe (1982). The determination of triglycerdes using enzymatic methods. Clin. Chem., 28: 2077-2081.

Fuhrman, B.; M. Rosenblat; T. Hayek; R. Coleman and M. Aviram (2000). Ginger extract consumption reduces plasma cholesterol, inhibits LDL oxidation and attenuates development of atherosclerosis in atherosclerotic, apolipoprotein Edeficient mice. Journal of Nutrition, 130: 11241131.

Furusho, T.; E. Kataoka; T. Yasuhara; M. Wada and S. Innami (2002). Administration of Bcarotene suppresses lipid peroxidation in tissues and improves the glucose tolerance ability of streptozotocin induced diabetic rats. International Journal of Vitamins and Nutrition Research, 72: 71-76.

Guenther, M. (1961). The essential oils. Vol. III, IV, 4th Ed.. D. Van Nostrand Company, Inc. New York.

Gupta, R.K.; A.N.K.; S. Diwakarc; A. Tyagia; V. Tandona; R. Chandraa and G. Watal (2008). In vivo evaluation of anti-oxidant and anti-lipidimic potential of Annona squamosa aqueous extract in Type 2 diabetic models. Journal of Ethnopharmacology, 118: 21-25.
Harris, E.H. (2005). Elevated liver function tests in type 2 diabetes. Clinical Diabetes, 23: 115-119. Hartnett, E.M.; R.D. Stratton; R.W. Browne; B.A. Rosner; R.J. Lanham and D. Armstrong (2000). Serum markers of oxidative stress and severity of diabetic retinopathy. Diabetes Care, 23: 234-240. Hassan, S.K.; N.M. El-Sammad; M.M. Ali; A.S.A. Hegazi and N.M. Nazif (2009). Anti-diabetic activity of syzygium cumini (I.) fruits extract on streptozotocin induced diabetic rats. Egypt. J. Biomed. Sci., 29: 271-285.

Henry, R.J. (1974). Clinical Chemistry, Principles and Technichs, $2^{\text {nd }}$ Edition, p. 525. Harper and Raw, New York.

Hwang, H.J.; S.W. Kim; J.M. Lim; J.H. Joo; H.O. Kim; H.M. Kim and J.W. Yun (2005). Hypoglycemic effect of crude exopolysaccharides produced by a medicinal mushroom Phellinus baumii in streptozotocin-induced diabetic rats. Life Sciences, 76: 3069-3080.

Jafarnejad, A.; S.Z. Bathaie; M. Nakhjavani; M.Z. Hassan (2008). Effect of spermine on lipid profile and HDL functionality in the streptozotocininduced diabetic rat model. Life Sciences, 82: 301-307.

Jarvull-Taylor, K.J.; R.A. Anderson and D.J. Graves (2001). A hydroxychalcone derived from cinnamon functions as a mimetic for insuin in 3T3L1 adipocytes. Journal of the American College of Nutrition, 20: 327-336.

Kannappan, S.; T. Jayaraman; P. Rajasekar; M.K. Ravichandran and C.V. Anuradha (2006). Cinnamon bark extract improves glucose metabolism and lipid profile in the fructose-fed rat. Singapore Med. J., 47: 858-863.

Kim, S.H.; S.H. Hyun and S.Y. Choung (2006). Anti-diabetic effect of cinnamon extract on blood glucose in $\mathrm{db} / \mathrm{db}$ mice. J. Ethnopharmacol, 104: 119-123.

Kim, M.J.; G.R. Ryu; J.S. Chung; S.S. Sim; D.J. Min Dos Rhie; S.H. Yoon; S.J. Hahn; M.S. Kim and Y.M. Jo (2003). Protective effect of epicatechin against the toxic effects of STZ on rat pancreatic islets: in vivo and in vitro. Pancreas, 26: 292299.

Lane Peter, W. and A.E.G. Person (1971). Dietary Requirements in the Laboratory: Animal Principles and Practice, p. 142. Acad. Press, New York.

Latha, M. and L. Pari (2003). Modulatory effect of Scoparia dulcis in oxidative stress-induced lipid peroxidation in streptozotocin diabetic rats. Journal of Medicinal Food, 4: 379-386. 
Lee, J.S.; S.M. Jeon; E.M. Park; T.L. Huk; O.S. Kwon; M.K. Lee and M.S. Cois (2003). Cinnamate supplementation enhances hepatic lipid metabolism and antioxidant defense systems in high cholesterol-fed rats. J. Med. Food, 6: 183191.

Lee, J.S. (2006). Effect of soy protein and genistein on blood glucose, antioxidant enzyme activities and lipid profile in streptozotocin-induced diabetic rats. Life Science, 78: 1578 - 1584.

Lutz, L.A. and W.M. Pardridge (1993). Insulin therapy normalizes glucose transporter mRNA but not immunoreactive transporter protein in streptozotocin diabetic rats. Metabolism, 42: 939-944.

Maiti, R.; D. Jana; U.K. Das and D. Ghosh (2004). Antidiabetic effect of aqueous extract of seed of Tarmarindus indica in streptozotocininduced diabetic rats. J. Ethnopharmacol, 92: 8591.

Maiti, R.; U.K. Das and D. Ghosh (2005). Attenuation of hyperglycemia and hyperlipidemia in streptozotocin induced diabetic rats by aqueous extract of seed of Tarmarindus indica. Biol. Pharm. Bull, 28: 1172-1176.

Mansour, H.A.; A.S.A. Newairy; M.I. Yousef and S.A. Sheweita (2002). Biochemical study on the effects of some Egyptian herbs in alloxan-induced diabetic rats. Toxicology, 170: 221-228.

McAuff, M.A.; F.O. Omoruy; E.Y. Morrison and H.N. Asemota (2003). Lipid management among coronary artery disease patients in diabetes mellitus or advanced age. Am. J. Cardiol, 87: 646-664. Meltzer, H.M.; M. Folmer; S. Wang; Q. Lie; A. Maage and H.H. Mundal (1997). Supplementary selenium influences the response to fatty acid induced oxidative stress in humans. Biological Trace Element Research, 60: 51-67.

Murugan, P. and L. Pari (2007). Influence of tetrahydrocurcumin on erythrocyte membrane bound enzymes and antioxidant status in experimental type 2 diabetic rats. Journal of Ethnopharmacology, 113: 479-486.

Myers, G.L.; W.G. Miller; J. Coresh; J. Fleming; N. Greenberg; T. Greene; T. Hostetter; A.S. Levey; M. Panteghini; M. Welch and J.H. Eckfeldt (2006). Recommendations for Improving Serum Creatinine Measurement: A Report from the Laboratory Working Group of the National Kidney Disease Education Program. Clinical Chemistry, 52: 5-18.

Ozlem, O.S.; Y. Refiye; O. Haci; O. Yasemin; Y. Aysen and T. Tugba (2006). Effects of parsley (Petroselinum crispum) extract versus glibornuride on the liver of streptozotocin-induced diabetic rats. Journal of Ethnopharmacology, 104: 175-181. Ozsoy-Sacan, O.; R. Yanardag; H. Orak; Y. Ozgey; A. Yarat and T. Tunali (2006). Effects of parsley (Petroselinum crispum) extract versus glibornuride on the liver of streptozotocin-induced diabetic rats. Journal of Ethnopharmacology, 104: 175-181.

Pacheco, Y.M.; R. Abia; J.S. Perona; M. Reina; V. Ruiz-Gutierrez; E.Y. Montero; F.J. Muriana (2001). Triacylglycerol rich lipoproteins interact with human vascular cells in a lipid dependent fashion. J. Agric. Food Chem., 49: 5653-5661.

Prasad, R.C.; B. Herzog; B. Boone; L. Sims and M. Waltner-Lawa. (2005).An extract of Syzygium aromaticum represses genes encoding hepatic gluconeogenic enzymes. Journal of Ethnopharmacology, 96: 295-301.

Pruneta-Deloche, V.; A. Sassolas; G.M. Dallinga-Thie; F. Berthezène; G. Ponsin and P. Moulin (2004). Alteration in lipoprotein lipase activity bound to triglyceride-rich lipoproteins in the postprandial state in type 2 diabetes. Journal of Lipid Research, 45: 859-865.

Qin, B.; M. Nagasaki; M. Ren; G. Bajotto; Y. Oshida and Y. Sato (2003). Cinnamon extract (traditional herb) potentiates in vivo insulinregulated glucose utilization via enhancing insulin signaling in rats. Diabetes Research and Clinical Practice, 62: 139-148.

Ramesh, B.; K.V. Pugalendi, (2005). Antihyperlipidemic and antidiabetic effects of Umbelliferone in streptozotocin diabetic rats. Yale J. Biol. Med., 78: 189-196.

Ramesh, B. and K.V. Pugalendi (2006a). Antioxidant role of Umbelliferone in STZdiabetic rats . Life Sci., 79: 306-310.

Ramesh, B. and K.V. Pugalendi (2006b). Influence of Umbelliferone on glycoprotein components in diabetic rats. Toxicol. Mech. Method, 17: 1-7. Ramesh, B.; P. Viswanathan and K.V. Pugalendi, (2007). Protective effect of Umbelliferone on membranous fatty acid composition in streptozotocin-induced diabetic rats. European Journal of Pharmacology, 566: 231-239.

Ravi, K.; S. Rajasekaran and S. Subramanian (2005). Antihyperlipidemic effect of Eugenia jambolana seed kernel on streptozotocin-induced diabetes in rats. Food Chem. Toxicol.,43:1433-1439. Ravi, K.; B. Ramchandran and S. Subramanian (2004a). Protective effect of Eugenia jambolana seed kernel on tissue antioxidants in streptozotocin induced diabetic rats. Biological and Pharmaceutical Bulletin, 27: 1212-1217. 
Ravi, K.; B. Ramchandran and S. Subramanian (2004b). Effect of Eugenia jambolana seed kernel on antioxidant defense system in streptozotocin induced diabetes in rats. Life Sci., 75: 2717-2731. Rotruck, J.J.; A.L. Pope; H.E. Ganther and A.B. Swanson (1973). Selenium: biochemical role as a component of glutathione peroxidase. Science, 179: 588-590.

Saravanan, G. and L. Pari (2008). Hypoglycaemic and antihyperglycaemic effect of syzygium cumini bark in streptozotocin- induced diabetic rats. J. Pharmacol Toxicol., 3: 1-10.

Scoppola, A.; F.R. Montecchi; G. Mezinger and A. Lala (2001). Urinarymevalonate excretion rate in type 2 diabetes: role of metabolic control. Atherosclerosis, 156: 357-361.

Sharma, S.B.; A. Nasir; K.M. Prabhu; P.S. Murthy and G. Dev (2003). Hypoglycaemic and hypolipidemic effect of ethanolic extract of seeds of Eugenia jambolana in alloxan-induced diabetic rabbits. J. Ethnopharmacol, 85: 201-206.

Snedecor, G.W. and W.G. Cochran (1980). Statistical Methods. $7^{\text {th }}$ Ed., p. 420. lowa Stat. Univ. Press, Ames, lowa, USA.

Srinivasan, K. (2005) .Spices as influencers of body metabolism: an overview of three decades of research. Food Research International, 38: 7786.

Srinivasan, K. and K. Sambaiah (1991). The effect of spices on cholesterol 7a-hydroxylase activity and on serum and hepatic cholesterol levels in the rat. International Journal for Vitamin and Nutrition Research, 61: 364-369.

Srinivasan, K.; B. Viswanad; L. Asrat; C.L. Kaul and P. Ramarao (2005). Combination of high-fat diet-fed and low-dose streptozotocin-treated rat: $A$ model for type 2 diabetes and pharmacological screening. Pharmacological Research, 52: 313320.

Stevens, L.A.; J. Coresh; T. Greene and S.L. Andrew (2006). Assessing kidney function measured and estimated glomerular filtration rate. N. England Journal of Medicine, 354: 24732483.

Subash Babu, P.; S. Prabuseenivasan and S. Ignacimuthu (2007). Cinnamaldehyde-A potential antidiabetic agent .Phytomedicine, 14: 15-22.

Szkudelski, T. (2001). The mechanism of alloxan and streptozotocin action in B-cells of the rat pancreas. Physiol. Res., 50: 537-546.

Temple, R.C.; P.M. Clark and C.N. Hales (1992). Measurement of insulin secretion in type 2 diabetes: problems and pitfalls. Diabetic Med., 9: 503-512.

Trinder, P. (1969). Determination of glucose in blood using glucose oxidase with an altemative oxygen acceptor. Am. Clin. Biochem., 6: 24-27.

Varley, H.; A. Gewenlock and M. Bell (1980). Practical Clinical Biochemistry. Vol. 1. $5^{\text {th }}$ Ed., pp. 741-897. London: William Heinemen Medical. Books, Ltd.

Venkateswaran, S. and L. Pari (2003). Effect of Coccinia indica levels on antioxidant status in streptozotocin-induced diabetic rats. Journal of Ethnopharmacology, 84: 163-168.

Vessal, M.; M. Hemmati and M. Vasei (2003). Antidiabetic effects of quercetin in streptozocininduced diabetic rats. Comparative Biochemistry and Physiology Part C, 135: 357-364.

Vijayakumar, M.; R. Govindarajan; G.M.M. Raoa; Ch.V. Raoa; A. Shirwaikar; S. Mehrotra and P. Pushpangadan (2006). Action of Hygrophila auriculata against streptozotocin-induced oxidative stress. Journal of Ethnopharmacology, 104: 356-361.

Wallach, J. (1992). Interpretation of Diagnostic Tests. A Synopsis of Aboratory Medicine, $5^{\text {th }}$ Ed. Little Brown \& Co., Boston, Mass., USA.

Waston, D.A. (1960). Simple method for the determination of serum cholesterol. Clin. Chem. Acta., 5: 589-596.

Wieland, H. and D. Seidel (1983). A fully enzymatic colorimetric determination of HDL-cholesterol in the serum. J. Nutr., 109: 760 - 766.

Yanardag, R.; S. Bolkent; A. Tabako glu-O־guz and O. Ozsoy-Sac an (2003). Effects of $\mathrm{Pe}$ troselinum crispum extract on pancreatic $B$ cells and blood glucose of streptozocin-induced diabetic rats. Biological and Pharmeutical Bulletin, 26: 1206-1210.

Yoon, B.I.; Y.K. Choi; D.Y. Kim; B.H. Hyun; K.H. Joo; H.J. Rim and J.H. Lee (2001). Infectivity and pathological changes in murine clonorchiasis: Comparison in immunocompetent and immunodeficient mice. J. Vet. Med. Sci., 63: 421-425.

Zari, T.A. and A.Sh. AL-Logmani (2009). Longterm effects of Cinnamomum zeylanicum Blume oil on some physiological parameters in streptozotocin-diabetic and non-diabetic rats. Boletín Latinoamericano y del Caribe de Plantas Medicinalesy Aromáticas, 8: 266 - 274. 